\title{
Steam Activation of Boron Doped Diamond Electrodes
}

Tatsuya Ohashi, Junfeng Zhang, Yoshio Takasu, ${ }^{1}$ Wataru Sugimoto, ${ }^{1, *}$

Department of Fine Materials Engineering, Faculty of Textile Science and

Technology, Shinshu University, 3-15-1 Tokida, Ueda, Nagano 386-8567, Japan

\begin{abstract}
Boron doped diamond (BDD) electrodes were activated in steam at various temperatures, resulting in high quality BDD electrodes with a porous microstructure. Distinct columnar structures were observed by scanning electron microscopy. The electrochemically active surface area of the steam-activated BDD was up to 20 times larger than the pristine BDD electrode owing to the porous texture. In addition, a widening of the potential window was observed after steam activation, suggesting that the quality of BDD was enhanced due to oxidative removal of graphitic impurities during the activation process.
\end{abstract}

Keywords: boron doped diamond; steam activation; porous material; double-layer capacitance

\footnotetext{
1 ISE member

* Corresponding author. Tel.: +81-268-21-5455; Fax: +81-268-21-5452

E-mail address: wsugi@shinshu-u.ac.jp (W. Sugimoto).
} 


\section{Introduction}

Boron-doped diamond (BDD) is a promising electrode material for various applications owing to its wide potential window, low background current and electrochemical stability compared with graphite electrodes [1]. The low background current originating from the high crystallinity and flat surface offers high signal/noise ratio for electrochemical sensors and electroanalysis applications [2, 3]. On the other hand, porous BDD with large surface area would be beneficial for electrocatalyst supports allowing high catalyst loadings [4]. High surface area would also be advantageous for electrolysis application, including waste water treatment [5], ozone [6] and $\mathrm{NF}_{3}$ production [7], since higher utilization of the BDD electrode and operation at higher current density can be realized. With the highest hardness of any bulk material, chemical etching is the preferred method for roughening of the diamond surface. Only two methods of fabricating porous BDD electrodes have been developed so far. Honeycomb structures with 30-400 nm diameter cylindrical pores have been fabricated by oxygen plasma etching through porous alumina masks [8]. Nanoscale pits and channels can also be prepared by catalytic etching of BDD with hydrogen gas using metal nanoparticles as catalysts [9-11]. In an attempt to develop a simple and scalable process for the fabrication of porous BDD electrodes, we adopted a classical activation process used for the preparation of activated carbons. Several activation methods are commonly used for the production 
of activated carbons $[12,13]$; e.g., $\mathrm{KOH}, \mathrm{CO}_{2}, \mathrm{O}_{2}, \mathrm{ZnCl}_{2}$, and steam activation. To the best of our knowledge, none of these activation methods have been applied to BDD electrodes. We report here for the first time, a simple steam-activation process to fabricate high quality BDD electrodes with a well-developed porous structure.

\section{Experimental}

Boron doped diamond (BDD) electrodes (Condias GmbH, 1300 ppm boron) synthesized by hot filament-assisted chemical vapor deposition (HFCVD) on a Nb substrate was used as received.

Steam activation of boron doped diamond (BDD) electrodes was conducted in the following manner.

The BDD electrode was placed in a silica boat with the BDD facing up, and set in a silica furnace tube. Ultrapure deionized water (millipore quality) was introduced into the silica furnace tube at 100 $\mathrm{mL} \mathrm{min}^{-1}$ with $\mathrm{N}_{2}(99.99995 \%)$ as the carrier gas at saturated vapor pressure $\left(40^{\circ} \mathrm{C}\right)$.

The furnace temperature was raised to the desired steam-activation temperature $(600,700,800$, $900^{\circ} \mathrm{C}$ ) at a rate of $5^{\circ} \mathrm{C} \mathrm{min}^{-1}$. The temperature was held at the respective temperatures for $2 \mathrm{~h}$ in the case for $600,700,800^{\circ} \mathrm{C}$ activation and for $1 \mathrm{~h}$ in the case of $900^{\circ} \mathrm{C}$, unless otherwise noted.

Gas chromatography (Shimadzu; GC-8A) equipped with an activated carbon column (GL Sciences, 30/60 mesh) was utilized to analyze the decomposed gases in the outlet (He carrier gas). A 
field emission-scanning electron microscope (FESEM; Hitachi S-5000) was used for morphological characterization. The microstructure of BDD was characterized by Raman spectroscopy (Kaiser Optical Systems, Inc., Raman Microscope System 3000) at room temperature with a YAG laser (excitation wavelength $532 \mathrm{~nm}$ ) as the excitation source. Contact angle measurements were performed with an automatic contact angle system (Drop Master Face; Kyowa Interface Science). Static sessile drop contact angle measurements were performed by measuring the contact angle $(\theta)$ between the BDD surface and a drop of ultrapure deionized water under ambient conditions. The measurement of the contact angle was performed $30 \mathrm{~s}$ after the drop placement on the surface in order to ensure that evaporation would not perturb the characterization.

Electrochemical measurements were conducted with an electrochemical cell equipped with the working electrode, a platinum mesh counter electrode, and an $\mathrm{Ag} / \mathrm{AgCl}$ (sat. $\mathrm{KCl}$ ) reference electrode. All electrode potentials throughout the paper are referred to the RHE scale. The BDD working electrode was set so that a geometric surface area of $0.181 \mathrm{~cm}^{2}$ was exposed to the electrolyte. Cyclic voltammetry was conducted in de-aerated $0.5 \mathrm{M} \mathrm{H}_{2} \mathrm{SO}_{4}$ electrolyte at room temperature with a potentio/galvanostat (Hokuto Denko; HZ-3000). Cyclic voltammograms were measured after 50 stabilization cycles at $500 \mathrm{mV} \mathrm{s}^{-1}$ within a potential window of $0.2-1.2 \mathrm{~V} \mathrm{vs}$. RHE. The electric double layer capacitance was calculated by averaging the cathodic and anodic charge 
measured between 0.2 and $1.2 \mathrm{~V}$ vs. RHE. The high and low potential limits was defined as the potential where $\Delta j / \Delta E<1 \mathrm{~mA} \mathrm{~V}^{-1} \mathrm{~cm}^{-2},(\Delta E=40 \mathrm{mV})$.

\section{Results and Discussion}

Typical FESEM images of the surface of steam-activated BDD electrodes treated at different temperatures are shown in Figs. 1 and 2. The surface of pristine BDD is characterized by a random orientation of microcrystals with the $\{111\}$ plane found as the most frequently exposed plane. Steam activation at $700^{\circ} \mathrm{C}$ resulted in the formation of numerous 10 to 100 -nm pits. SEM images at low resolution (Fig. 2) reveal that the steam-activation phenomenon proceeds homogeneously throughout the BDD electrode surface. Triangular pits and islands can be distinguished at a steam-activation temperature of $700^{\circ} \mathrm{C}$, most likely reflecting the atomic arrangement of the $\{111\}$ plane (Fig. 3). Similar morphology (preferential etching) with shallow triangular pits has been reported for oxidative etching of non-doped synthetic diamond $\{111\}$ surfaces using oxygen/water vapor, albeit in much larger scales, tens micrometers [14]. The triangular pits presumably have their sides pointing towards the $<\overline{1} 12>$ directions, while the islands point in the opposite directions. Higher activation temperatures lead to rigorous corrosion of the BDD surface forming a highly porous structure with a columnar texture (Fig. 2). The thickness of the walls is in the order of nanometers and the diameter 
of the pits is a few hundred nanometers, about the same scale as the crystallite size of BDD.

Progressive etching was observed when the steam activation time was extended to $2 \mathrm{~h}$ at $900^{\circ} \mathrm{C}$ (Fig.

4) instead of $1 \mathrm{~h}$ (Figs. 1(d) and 2(d)), however the etching was too severe and the electrode was too brittle to handle.

Characterization of the outlet gas by gas chromatography revealed carbon monoxide and hydrogen as by-products above $700^{\circ} \mathrm{C}$. The amount of the by-products increased with increasing activation temperature. The reaction can be simplified as below, which is similar to the case for the carbon-steam reaction mechanism [15].

$$
\mathrm{C}(\text { diamond })+\mathrm{H}_{2} \mathrm{O} \rightarrow \mathrm{CO}+2 \mathrm{H}_{2}
$$

Contact angle measurements of steam-activated BDD revealed a change in the hydrophobicity of the surface (Fig. 5). The water contact angle for pristine BDD was $56^{\circ}$. As the steam-activation temperature is raised, the contact angle decreased and BDD steam-activated at $700^{\circ} \mathrm{C}$ showed a hydrophilic character with a contact angle of $17^{\circ}$. The conversion from hydrophobic to hydrophilic surfaces has been reported to occur after anodic treatment or photochemical oxidation of BDD, and has been suggested to be linked to the conversion of hydrogen terminated surfaces to oxygenated surfaces $[16,17]$. The decrease in water contact angle of the steam-activated BDD up to $700^{\circ} \mathrm{C}$ is thus attributed to enrichment in oxygen-terminated and/or oxygen surface functional groups, such as 
$\mathrm{C}=\mathrm{O}, \mathrm{C}-\mathrm{O}-\mathrm{C}$, and $\mathrm{C}-\mathrm{OH}$. Further increase in steam-activation temperature changes the surface back to a hydrophobic one. We postulate that the hydrophobicity is stimulated by the roughened surface, as porous surfaces are more hydrophobic than flat ones [18].

The change in surface area of BDD after steam activation was probed electrochemically. The capacitance per unit geometric surface area should be proportional to the roughness of the electrode material, i.e. the real surface area per unit geometric area, as long as that the capacitance per real surface area is constant. Cyclic voltammograms of activated BDD electrodes in $0.5 \mathrm{M} \mathrm{H}_{2} \mathrm{SO}_{4}$ between -0.5 and $2.5 \mathrm{~V}$ are shown in Fig. 6A. The electric double layer capacitance per geometric surface area for the as-received BDD was $11 \mu \mathrm{F} \mathrm{cm}^{-2}$, in good agreement with an earlier study [8]. A clear increase in electric double layer capacitance is observed for the electrodes treated above $700^{\circ} \mathrm{C}$ (Fig. 6A inset and Table 1), in accord with the surface roughening observed by SEM. The electric double layer capacitance increases with the increase in activation temperature, reaching $234 \mu \mathrm{F} \mathrm{cm}{ }^{-2}$ at $900^{\circ} \mathrm{C}$ activation (21 times compared to pristine BDD). An apparent tilting of the cyclic voltammograms is observed after steam-activation (Fig. 6A inset). Figure 6B shows the cyclic voltammograms taking into account of the enhancement in roughness (current divided by the roughness enhancement factor). Clearly, the cyclic voltammograms are all comparable (Fig. 6B inset) and the steam-activation does not have any negative effect on the conductivity of BDD, i.e., 
the steam-activation process does not induce any increase in electrode resistance. In addition to the increase in electrochemically active surface area, a wider potential window, one of the most important aspects of BDD electrodes, was observed after steam activation (Fig. 6B). The potential window for steam activated $\mathrm{BDD}$ at $900^{\circ} \mathrm{C}$ was $3.00 \mathrm{~V}$, appreciably larger than that for pristine BDD of $2.61 \mathrm{~V}$ (Table 1). It is noteworthy that oxygen plasma etching of BDD through porous alumina masks lead to a slight decrease in the electrochemical potential windows (3.04 V to $2.46-2.70 \mathrm{~V})[8]$

Raman spectroscopy was conducted to study the microstructural differences before and after treatment and check for possible damage to the diamond structure induced by steam activation. Figure 7 shows the Raman spectra of steam-activated BDD. The peak at $1210 \mathrm{~cm}^{-1}$ is attributed to disordered diamond structure $[19,20]$. The peak at $480 \mathrm{~cm}^{-1}$ is observed in heavily doped BDD and is related to the phonon scattering at boron induced structural modifications [20]. This peak is known to shift with different levels of boron doping [20]. No shift was observed after steam activation, suggesting that the boron concentration in BDD was unchanged. The $1330 \mathrm{~cm}^{-1}$ is assigned to the $s p^{3}$-bonded carbon in diamond (D band) and reflects the high crystallinity of the film [21]. The weak broad peak at $1580 \mathrm{~cm}^{-1}$ is attributed to the $s p^{2}$-bonded carbon ( $\mathrm{G}$ band), often found as minor impurities in BDD electrodes prepared by hot-filament assisted CVD [22]. The peak intensity ratio 
of the $\mathrm{D}$ band to the $\mathrm{G}$ band $\left(I_{\mathrm{D}} / I_{\mathrm{G}}\right)$ is a measure of the amount of graphitic impurities. As shown in

Fig. 7 inset, $I_{\mathrm{D}} / I_{\mathrm{G}}$ increases as the activation temperature is raised. As the $s p^{2}$-bonded carbon is more vulnerable to corrosion than $s p^{3}$ carbon, the relative amount of $s p^{2}$ carbon decreases as the activation temperature is raised. Thus, steam activation results in preferential gasification of impurity $s p^{2}$ carbon. The shoulder peak around 2.1 to $2.4 \mathrm{~V}$ vs. RHE observed in the cyclic voltammograms of pristine BDD is assigned to the oxidation of the $s p^{2}$ carbon impurity [22, 23]. The shoulder peak decreased with increasing steam activation temperature, resulting in an increase in potential window. Therefore, steam activation induces an increase in the electrochemically active surface area of BDD, and simultaneously widens the available potential window by removing $s p^{2}$-bonded carbon.

Apparently, the etching rate is different for different crystal planes, as the pits seem to develop more on particular surfaces. Specific planes seem to be are more resistive to steam activation, leaving behind thin walls. It is noteworthy that the surface of the pits (side of walls) is smooth, most likely reflecting preferential corrosion along a specific crystal plane. Based on the obtained results, the steam-activation mechanism of BDD is schematically illustrated in Fig. 8. The initial step in the steam activation is most likely the oxidative removal of $s p^{2}$-bonded carbon. The next step should be etching of the $\{111\}$ planes, since triangular pits and islands were observed when the 
steam-activated temperature was $700^{\circ} \mathrm{C}$. As the steam-activation is raised, etching proceeds deeper into the film. The $\{100\}$ plane is less vulnerable to etching, leaving behind a columnar texture.

\section{Conclusions}

Steam activation of boron-doped diamond (BDD) electrodes was conducted in an attempt to prepare porous BDD. Triangular pits and islands, most likely reflecting the atomic arrangement of the $\{111\}$ plane, were formed by steam-activation at $700^{\circ} \mathrm{C}$. Higher activation temperatures lead to rigorous corrosion of the BDD surface forming a highly porous structure with a columnar texture.

The electrochemically active surface area of the steam-activated BDD was up to 20 times larger than the pristine BDD electrode owing to the porous texture. In addition, a widening of the potential window was observed after steam activation, suggesting that the quality of BDD was enhanced due to oxidative removal of graphitic impurities during the activation process. The BDD used in this study was prepared by hot filament-assisted chemical vapor deposition which allows large scale production (up to $0.3 \mathrm{~m}^{2}$ ) applicable to industrial applications but in general have higher content of graphitic $s p^{2}$ carbon impurity compared to other methods [1]. The method developed in this study should offer a simple, low cost, environmentally benign, scalable process to fabricate high quality porous BDD electrodes with high surface area and a wide potential window, finding pervasive use in electrolysis and as a durable electrocatalyst support. 


\section{Acknowledgements}

This work was supported in part by a Grant in-Aid for Global COE Program of the Ministry of

Education, Culture, Sports, Science and Technology (MEXT), Japan.

\section{References}

[1] A. Fujishima, Y. Einaga, T. N. Rao, D.A. Tryk, Diamond Electrochemistry, Elsevier

Amsterdam-BKC, Tokyo, 2005.

[2] M. Chiku, J. Nakamura, A. Fujishima, Y. Einaga, Anal. Chem. 80 (2008) 5783.

[3] A. Suzuki, T.A. Ivandini, K. Yoshimi, A. Fujishima, G. Oyama, T. Nakazato, N. Hattori, S.

Kitazawa, Y. Einaga, Anal. Chem. 79 (2007) 8608.

[4] K. Honda, M. Yoshimura, T. N. Rao, D.A. Tryk, A. Fujishima, K. Yasui, Y. Sakamoto, K.

Nishio, H. Masuda, J. Electroanl. Chem. 514 (2001) 35.

[5] J. Iniesta, P. A. Michaud, M. Panizza, G. Cerisola, A. Aldaz, Ch. Comninellis, Electrochim. Acta $46(2001) 3573$.

[6] N. Katsuki, E. Takahashi, M. Toyoda, T. Kurosu, M. Iida, S. Wakita, Y. Nishiki, T. Shimamune,

J. Electrochem. Soc. 145 (1998) 2358. 
[7] M. Shizuno, K. Nakanishi, M. Inaba, M. Uno, Y. Nishiki, T. Furuta, A. Tasaka, ECS

Transactions $16(2009) 1$.

[8] K. Honda, T. N. Rao, D. A. Tryk, A. Fujishima, M. Watanabe, K. Yasui, H. Masuda, J.

Electrochem. Soc. 148 (2001) A668.

[9] S. Konishi, T. Ohashi, W. Sugimoto, Y. Takasu, Chem. Lett. 35 (2006) 1216.

[10] Y. Takasu, S. Konishi, W. Sugimoto, Y. Murakami, Electrochem. Solid-State Lett. 9 (2006)

C114.

[11] T. Ohashi, W. Sugimoto, Y. Takasu, Electrochim. Acta 54 (2009) 5223.

[12] A. Ahmadpour, D. D. Do, Carbon 34 (1996) 471.

[13] D. D. Eley, P. W. Selwood, P. B. Weisz, in Advances in Catalysis XI, Academic Press, New

York and London, 1959, pp. 134-178.

[14] F. K. de Theije, E. van Veenendaal, W. J. P. Van Enckevort, E. Vlieg, Surf. Sci. 492 (2001) 91.

[15] F.J. Long and K.W. Sykes, Proc. Roy. Soc. A193 (1948) 377.

[16] R. Boukherroub, X. Wallart, S. Szunerits, B. Marcus, P. Bouvier, M. Mermoux, Electrochem.

Commun. 7 (2005) 937.

[17] I. Duo, C. Levy-Clement, A. Fujishima, Ch. Comninellis, J. Appl. Electrochem. 34 (2004) 935.

[18] X. J. Feng, L. Jiang, Adv. Mater. 18 (2006) 3063. 
[19] R. G. Buckley, T. D. Moustakas, L. Ye, J. Varon, J. Appl. Phys. 66 (1989) 3595.

[20] F. Pruvost, E. Bustarret, A. Deneuville, Diamond Related Mater. 9 (2000) 295.

[21] M. C. Granger, M. Witek, J. Xu, J. Wang, M. Hupert, A. Hanks, M. D. Koppang, J. E. Butler, G.

Lucazeau, M. Mermoux, J. W. Strojek, G. M. Swain, Anal. Chem. 72 (2000) 3793.

[22] H. B. Martin, A. Argoitia, U. Landau, A. B. Anderson, J. C. Angus, J. Electrochem. Soc. 143

(1996) L133.

[23] J. A. Bennett, J. Wang, Y. Show, G. M. Swain, J. Electrochem. Soc. 151 (2004) E306.

\section{Figure captions}

Fig. 1. Typical high-magnification SEM images of BDD electrodes; (a) pristine and steam-activated

at (b) 700, (c) 800 , and (d) $900^{\circ} \mathrm{C}$. (b) and (c) were treated for $2 \mathrm{~h}$, and (d) for $1 \mathrm{~h}$.

Fig. 2. Typical low-magnification SEM images of BDD electrodes; (a) pristine and steam-activated

at (b) 700, (c) 800, and (d) $900^{\circ} \mathrm{C}$. (b) and (c) were treated for $2 \mathrm{~h}$, and (d) for $1 \mathrm{~h}$.

Fig. 3. Enlarged SEM images of steam-activated BDD prepared at $700^{\circ} \mathrm{C}$ and schematic illustration of possible orientation of positive and negative pits on the diamond $\{111\}$ surface. Some of the pits and islands are highlighted in blue and red, respectively for visual imaging. 
Fig. 4. Typical (a) high and (b) low-magnification SEM images of a BDD electrode steam-activated at $900^{\circ} \mathrm{C}$ for $2 \mathrm{~h}$.

Fig. 5. Water contact angle photographs and contact angles as a function of the steam-activation temperature.

Fig. 6. (A) Cyclic voltammograms of BDD electrodes at $100 \mathrm{mV} \mathrm{s}^{-1}$ in $0.5 \mathrm{M} \mathrm{H}_{2} \mathrm{SO}_{4}$; (a) pristine and steam-activated at (b) 700 , (c) 800 , and (d) $900^{\circ} \mathrm{C}$. (B) Voltammograms from (A) with the current normalized taking into account the enhancement in roughness.

Fig. 7. Raman spectra of BDD electrodes; (a) pristine and steam-activated at (b) 700, (c) 800, and (d) $900^{\circ} \mathrm{C}$. Inset shows the $I_{\mathrm{D}} / I_{\mathrm{G}}$ at the different temperatures.

Fig. 8. Schematic illustration of the steam-activation process of BDD electrode. 
Table 1. Electrochemical properties of steam-activated BDD.

\begin{tabular}{cccc}
\hline $\begin{array}{c}\text { Steam activation } \\
\text { condition }\end{array}$ & $\begin{array}{c}\text { Specific capacitance } \\
{[\mathrm{a}] / \mu \mathrm{F} \mathrm{cm}^{-2} \text { geometric }}\end{array}$ & $\begin{array}{c}\text { Enhancement } \\
\text { factor }[\mathrm{b}] /-\end{array}$ & $\begin{array}{c}\text { Potential } \\
\text { window }[\mathrm{c}] / \mathrm{V}\end{array}$ \\
\hline as-received & 11 & 1 & 2.61 \\
$700^{\circ} \mathrm{C}$ for $2 \mathrm{~h}$ & 57 & 5 & 2.91 \\
$800^{\circ} \mathrm{C}$ for $2 \mathrm{~h}$ & 103 & 9 & 2.93 \\
$900^{\circ} \mathrm{C}$ for $1 \mathrm{~h}$ & 234 & 21 & 3.00 \\
\hline
\end{tabular}

[a] Calculated by averaging the anodic and cathodic charge between $0.2-1.2 \mathrm{~V}$ vs. RHE from Fig. 6.

[b] The geometric capacitance of electrodes normalized by the geometric capacitance of as-received BDD.

[c] The potential window is defined as the potential region where $\Delta j / \Delta E<1 \mathrm{~mA} \mathrm{~V}^{-1} \mathrm{~cm}^{-2}$. 

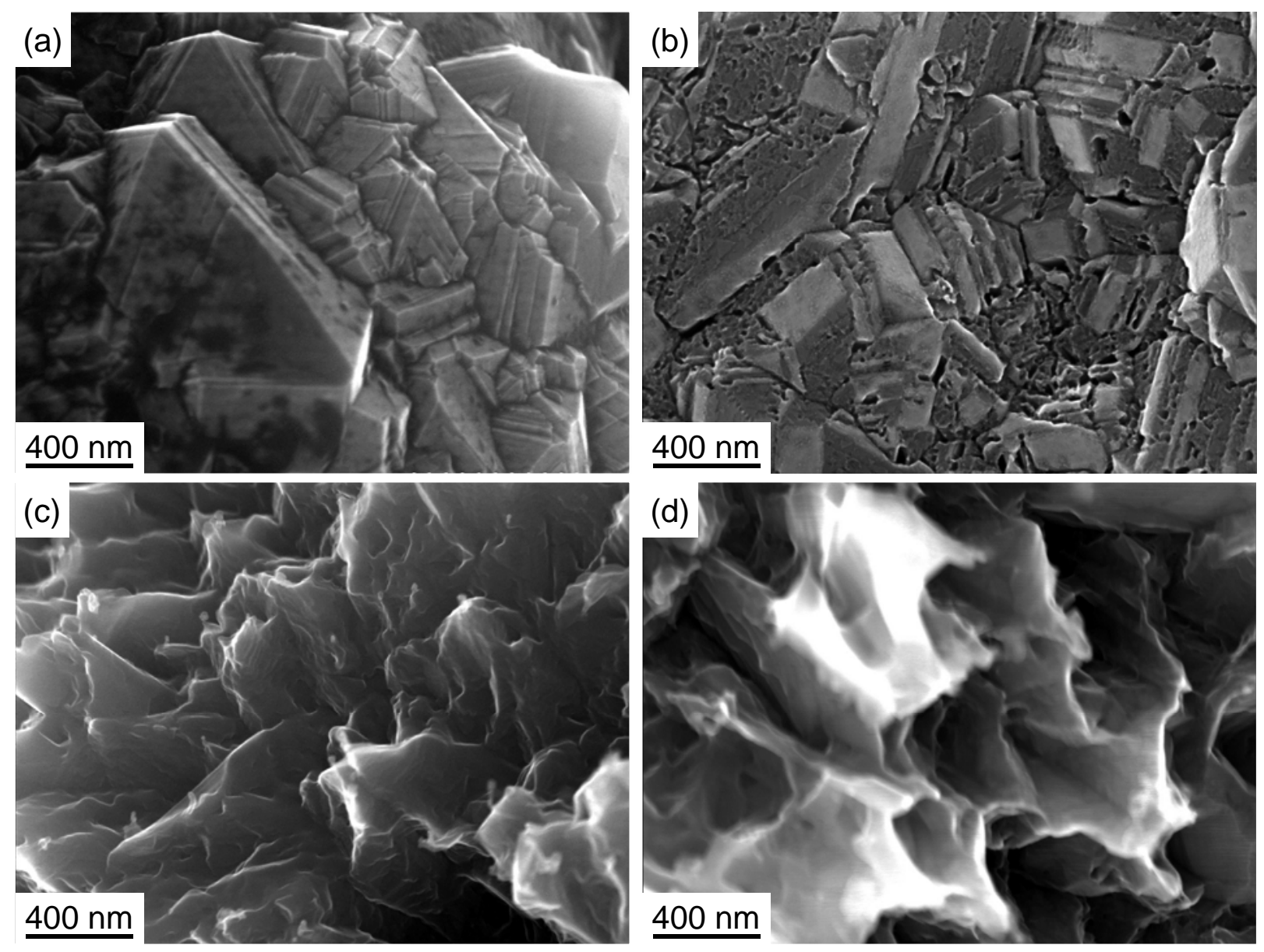

Fig. 1 

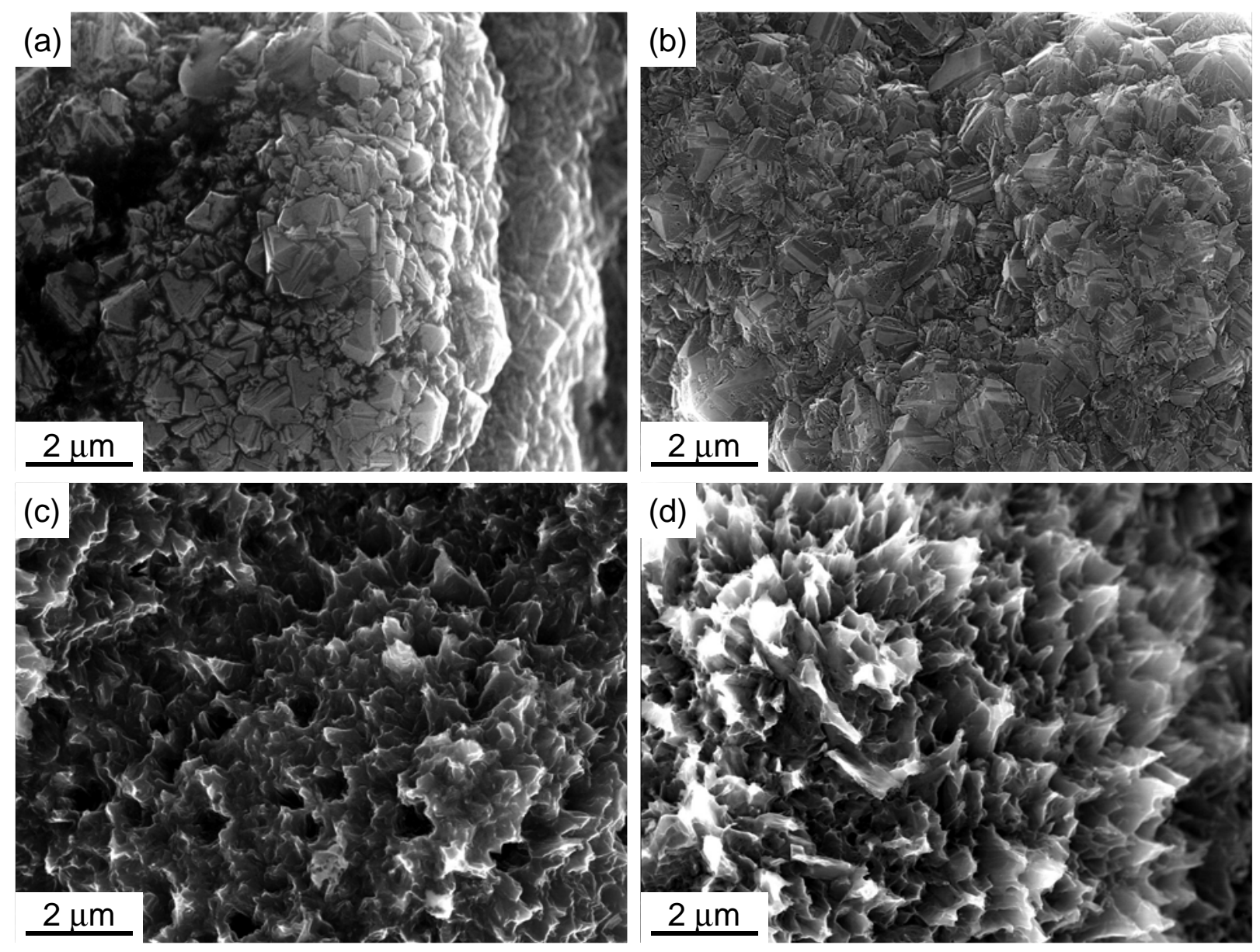

Fig. 2 


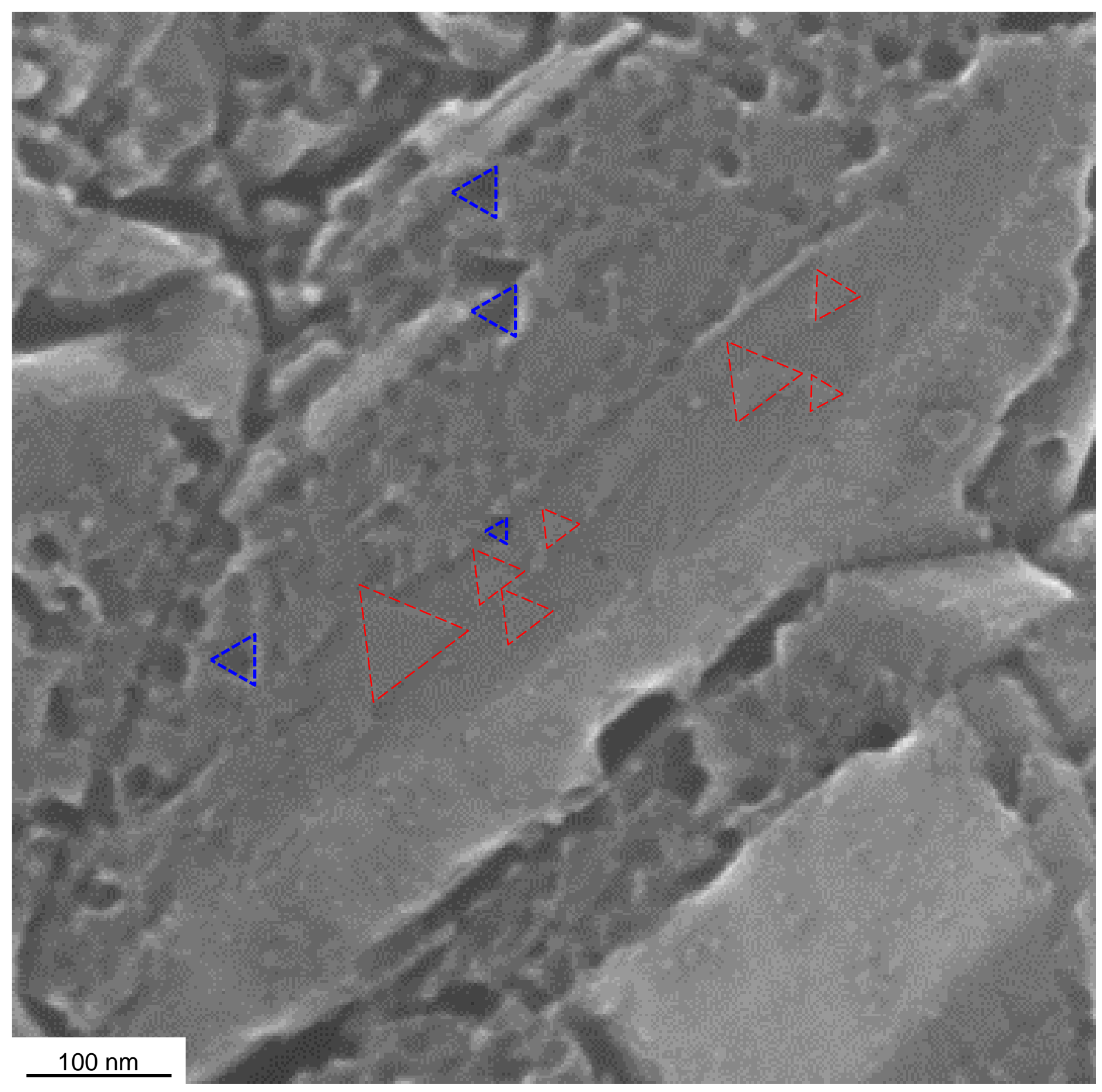

nm

Fig. 3

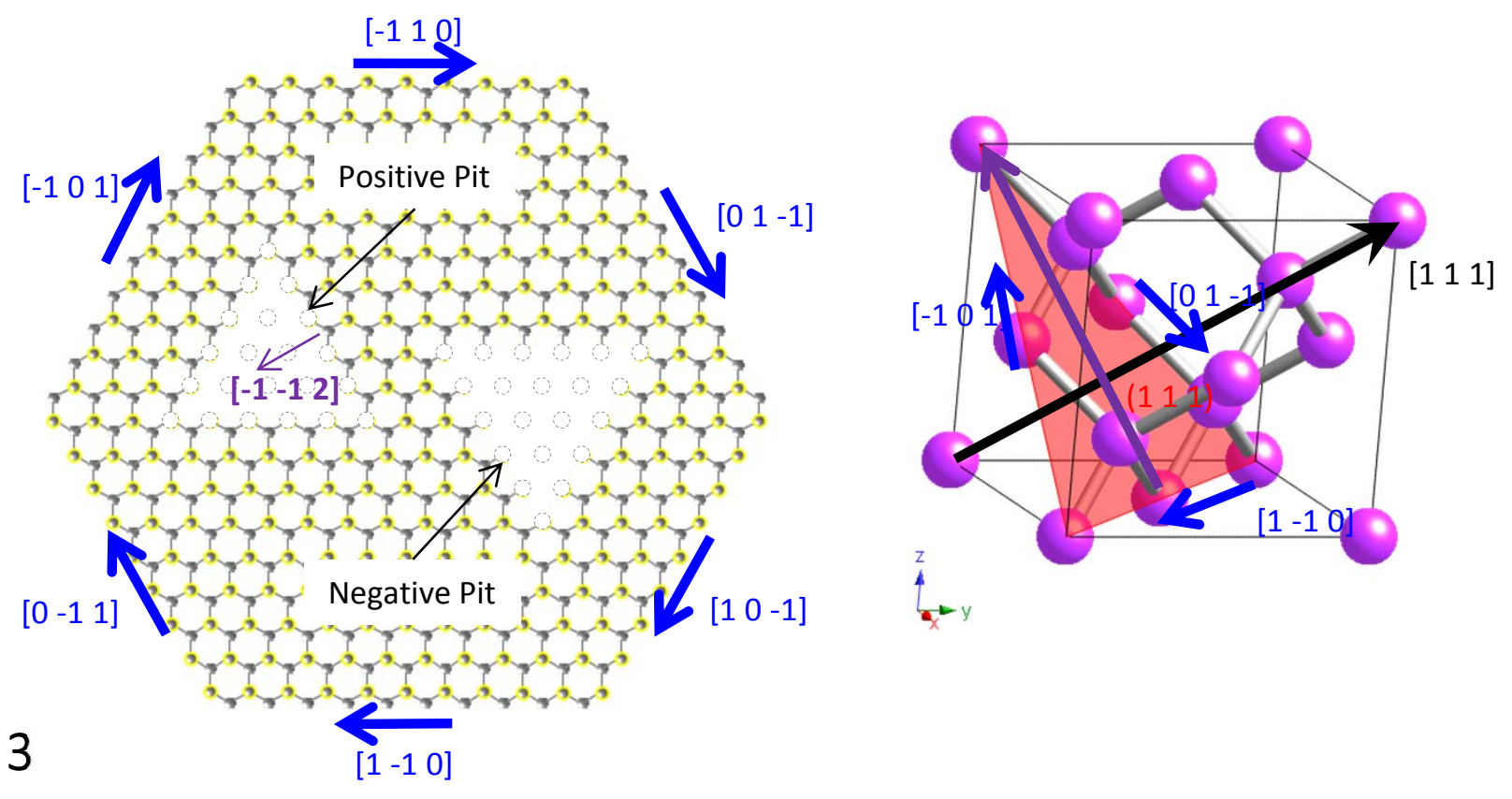




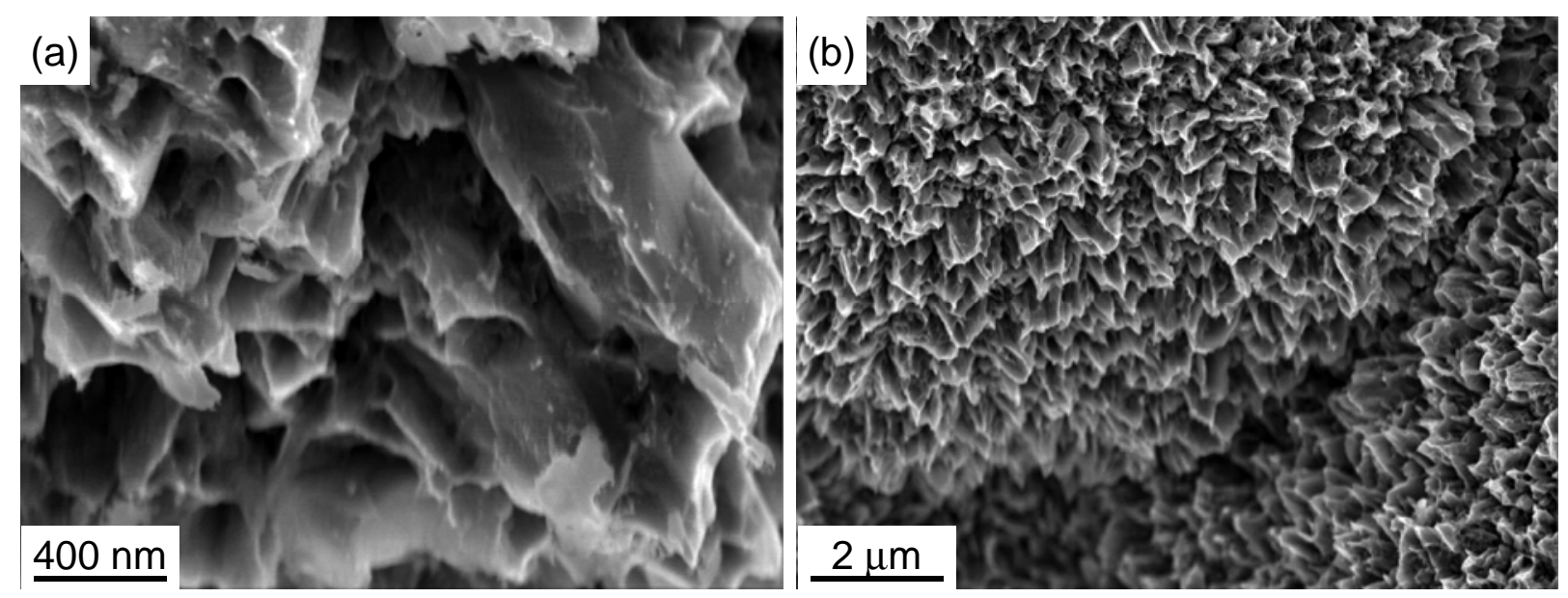

Fig. 4 


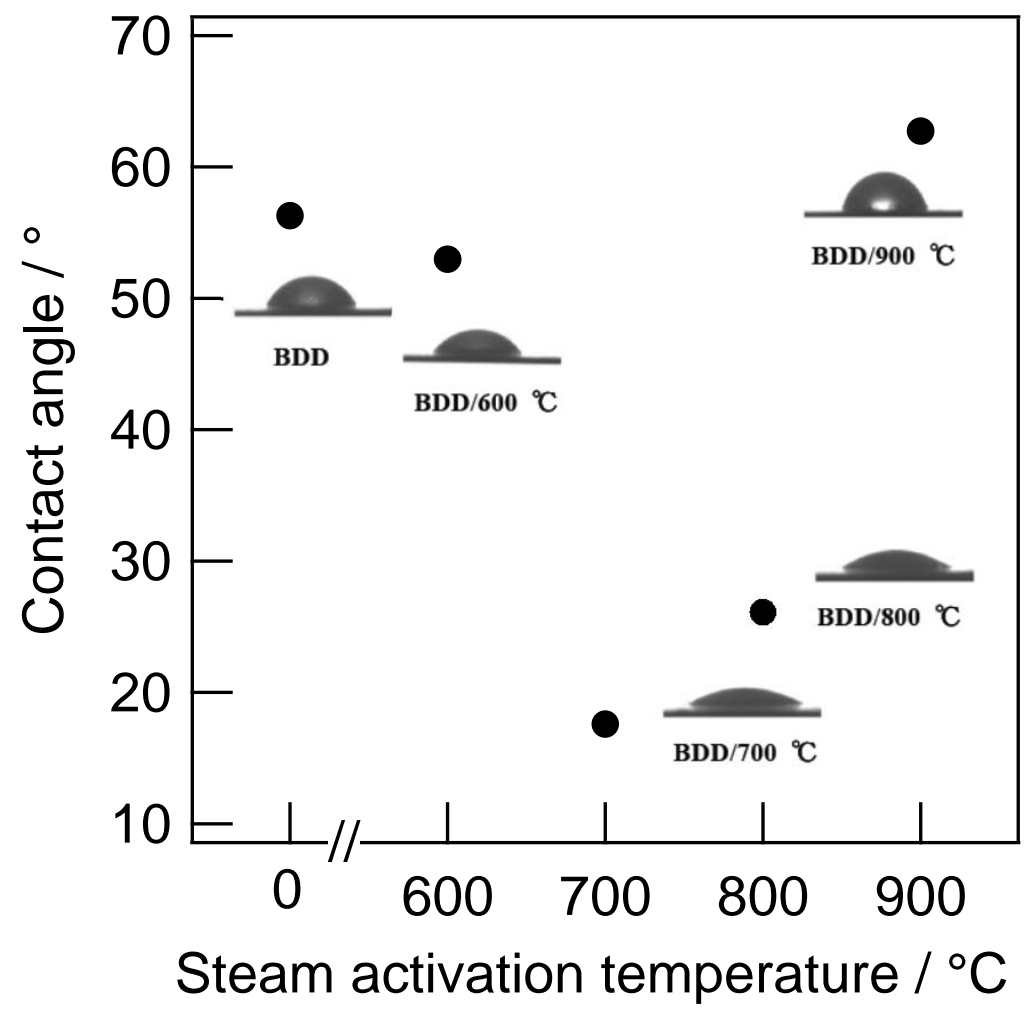

Fig. 5 

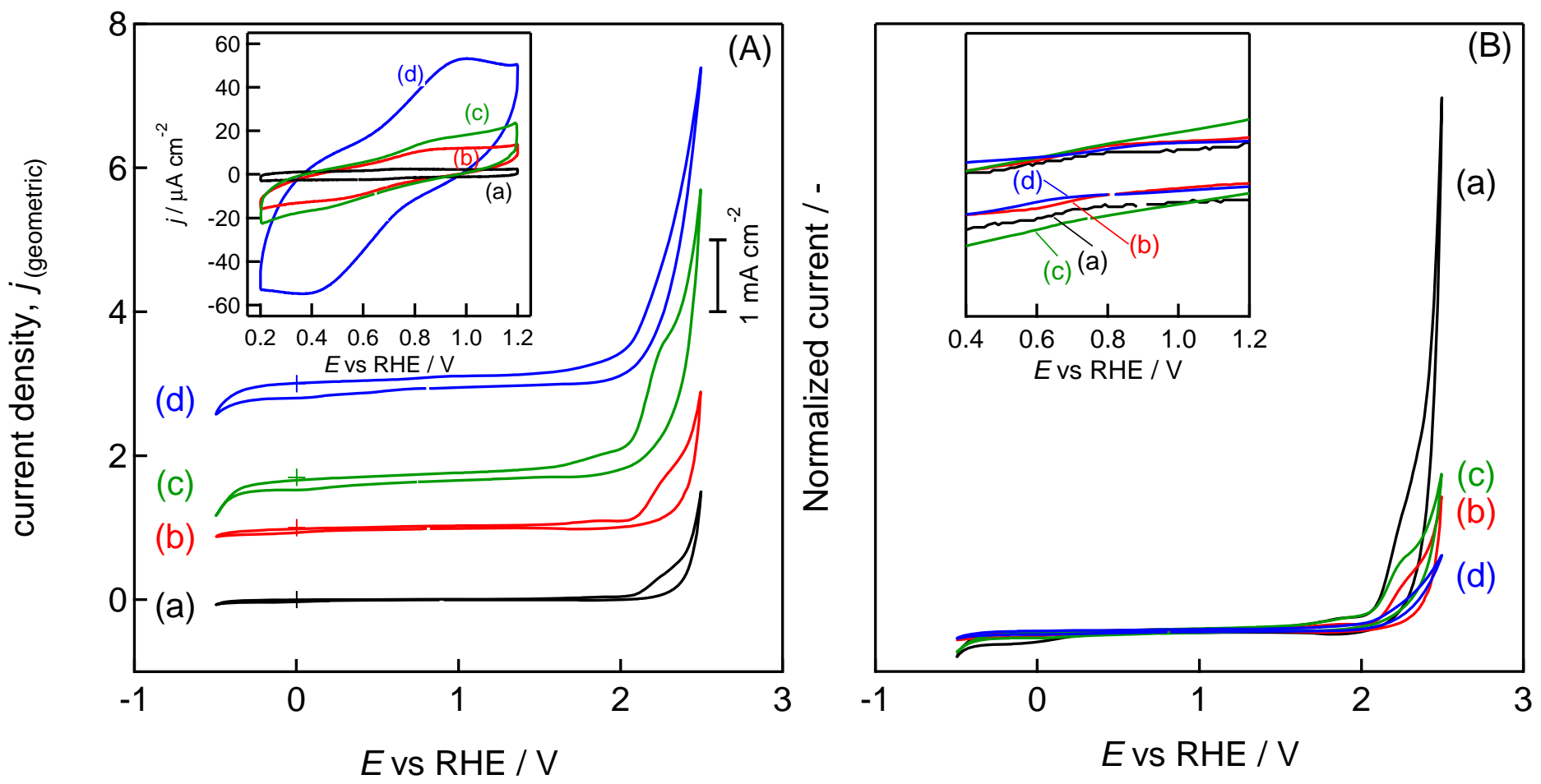

Fig. 6 


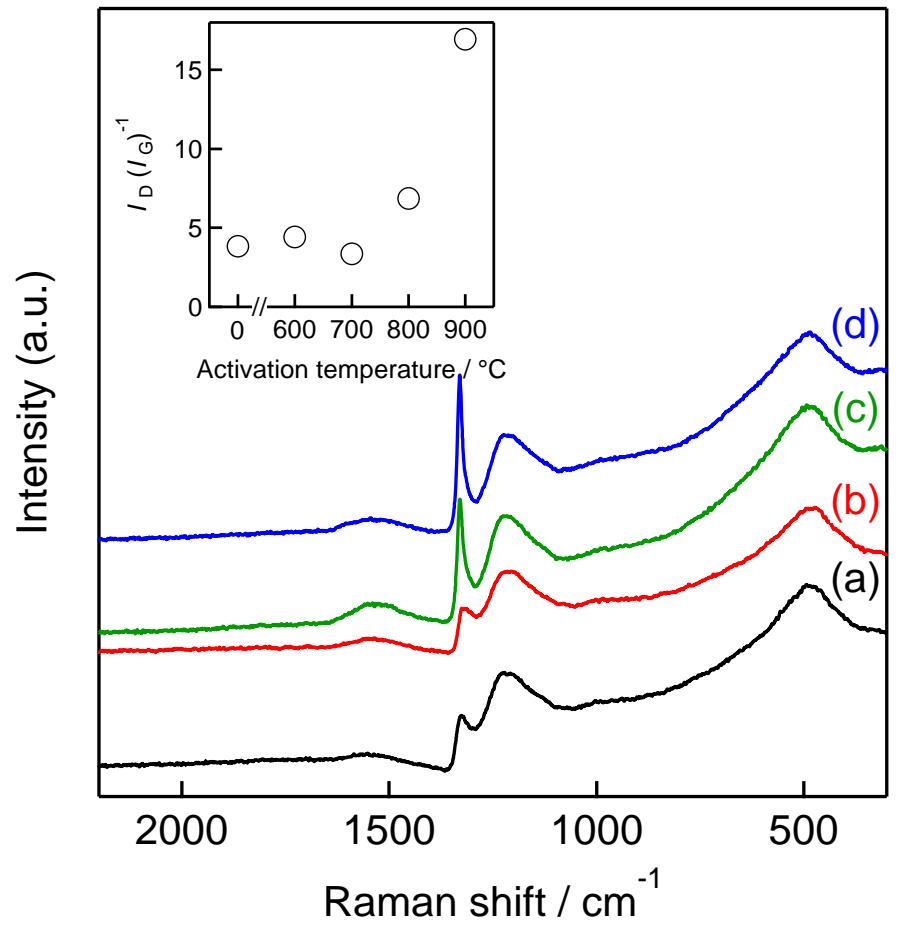

Fig. 7 

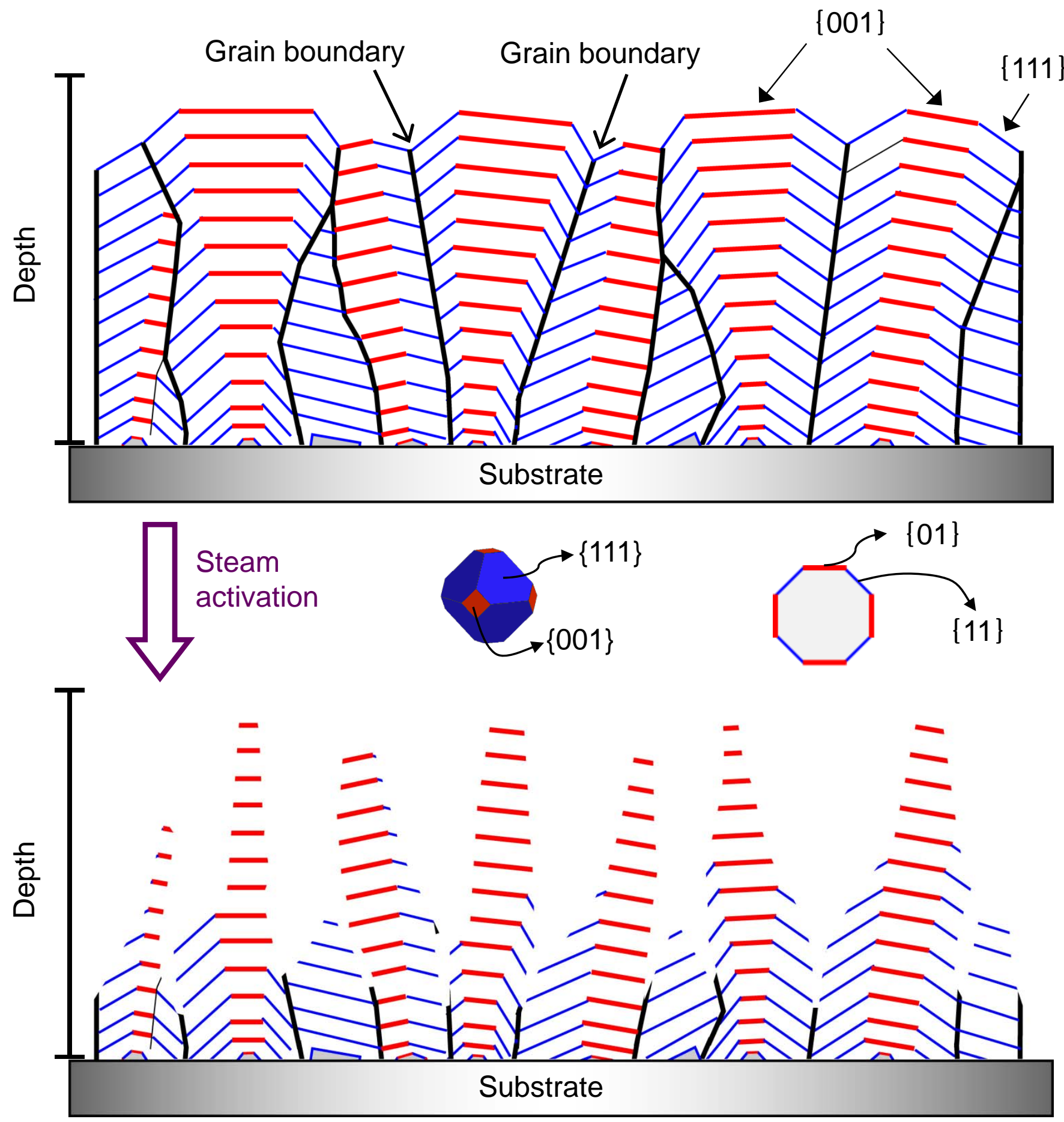

Fig. 8 